\title{
A Learning Model for the Introduction of the Principles of Bioclimatics and Sustainability in the Education of Pre-service Teachers
}

\author{
Alexandra Gkioka ${ }^{1}$, Ana Leci ${ }^{2}$, Dimitris Stavridis ${ }^{3} \&$ Fanny Seroglou $^{4}$
}

\begin{abstract}
:
In this paper, we present the design, implementation and results of a teaching strategy that introduces pre-service teachers to environmental issues and basic bioclimatics. Student-teachers create digital narratives re-contextualizing simple sustainability principles and ideas. In our research, 200 students participated, at the School of Primary Education of the Faculty of Education at the Aristotle University of Thessaloniki in Greece, during the academic year 2013-2014. Our research follows 6 steps:

Step 1: Individual interviews and questionnaire distribution to record understanding and habits about energy resources and the environment

Step 2: Introduction to current environmental issues and discussion on environmental values and attitudes.

Step 3: Teaching activities that require active collaborative participation of pre-service teachers in a wiki.

Step 4: Production of digital narratives.

Step 5: Individual interviews and questionnaire distribution to record the impact of our application.

Step 6: The recorded interviews, the questionnaires and the developed digital narratives are analyzed using the GNOSIS research model (Guidelines for Nature of Science Introduction to Scientific literacy).

Data analysis initially shows encouraging results in terms of pre-service students re-contextualizing bioclimatics and sustainability concepts and attitudes.
\end{abstract}

Keywords: teacher education, bioclimatics, sustainability, wiki, digital narratives

\section{Introduction}

A proposal for the training of educators on sustainability issues through a learning model that combines principles of science regarding the saving of energy and natural resources together with issues of the protection of the environment is presented in this paper. The incentive for the creation of this particular model is the realization that due to pressing developments concerning global warning there is a constant need for information and investigation of all the parameters that may lead to sustainability, while teachers are particularly competent at handling the diffusion of this information to the pupils and the society. The teaching proposal deals with the following issues: a) man-

ATLAS Research Group, School of Primary Education, Faculty of Education, Aristotle

University of Thessaloniki, 54124, Thessaloniki, Greece.

${ }^{1} \mathrm{PhD}$ student in science education.

${ }^{2}$ Postgraduate student in science education.

3ICT teacher.

${ }^{4}$ Assistant Professor in science education. 
made environment and the problems that derive from its expansion, b) sustainability, so that human activity will not destroy nature, c) bioclimatic planning, that aims at the improvement and the protection of the environment and the natural resources. Under this framework, original teaching material has been developed concerning bioclimatics and sustainability, materialized through multimedia applications and activities placed in a research-based designed educational wiki. The teaching program aims to inform and encourage values and attitudes towards environmental issues, to help students recontextualize the teaching content and provide activities that require active cooperational participation of the students. The educational proposal has been formed as an alternative teaching approach compared to traditional instruction, trying to incorporate contemporary ideas and ways of learning (Cunningham et al., 1993; Osberg, 1995; Seroglou 2006), introducing students to bioclimatics and sustainability principles and encouraging them to present their own ideas and proposals uploading them in digital form on a specially designed educational wiki in order to communicate with each other and open the discussion to society.

\section{Methodology}

The application of the developed course on bioclimatics and sustainability has taken place at the School of Primary Education at the Faculty of Education at the Aristotle University of Thessaloniki in Thessaloniki (Greece) during the academic year 2013-2014 and has been completed in 4 workshops (each one having 180 minutes duration) with the participation of 200 student-teachers. Our research has followed 6 steps:

Step 1: Individual interviews have taken place and pre-test questionnaires have been distributed to the participants in order to record student-teachers' understanding and habits about energy resources and the environment. The initial analysis of the results of the pre-test questionnaires has pointed out the necessity for student-teachers to be informed about issues concerning energy management, control on use of natural resources, bioclimatics and ways for improving environmental conditions.

Step 2: Introduction to current environmental issues and discussion on environmental values and attitudes takes place. Educational material that included suggestions on environmental issues with the use of images and films is presented to the students in order to inform them about the causes and consequences of the environmental crisis and the appropriate management of natural reserves and bio-climate. For the presentation, digital means are used such as PowerPoint, films created using Microsoft Movie Maker and comics designed using Cosy Comic Strip Creator (Figures 1, 2, 3). Students' suggestions support: a) saving natural resources b) energy and the problems that derive from its use, c) the use of energy sources that can ensure sustainability d) the bioclimatic planning for the improvement of living conditions. 

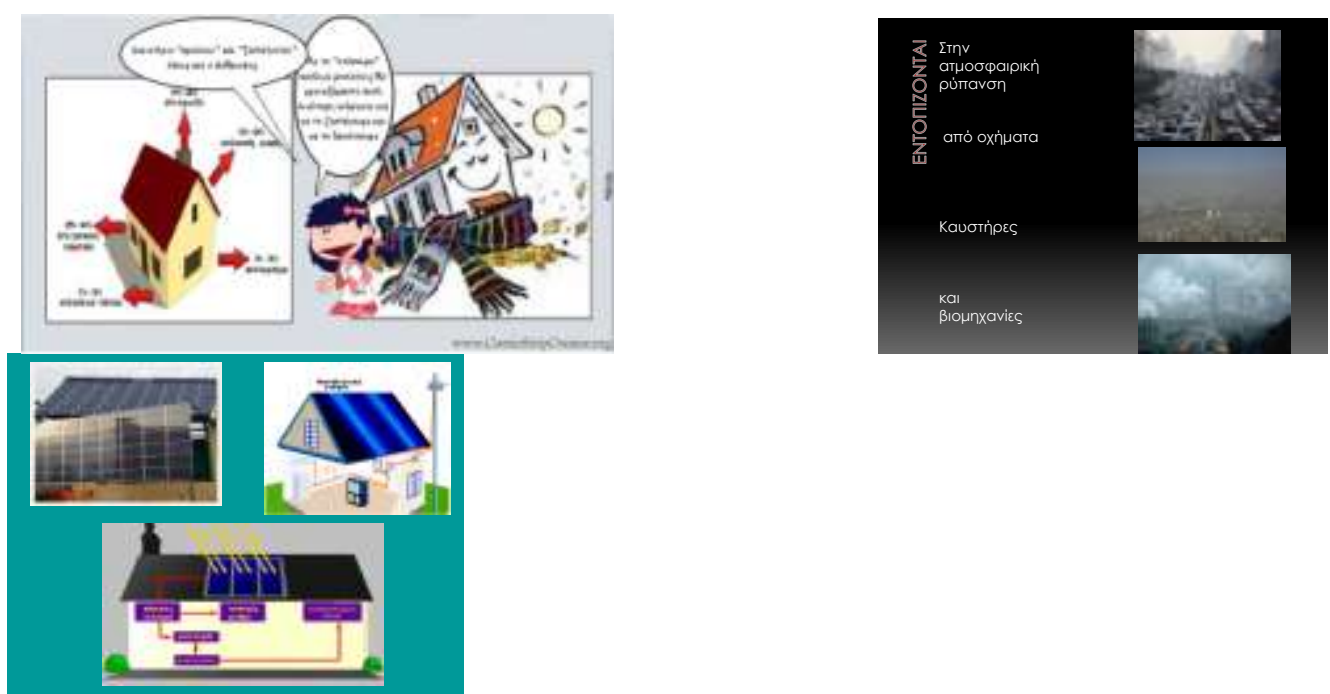

Figure 1: introducing bioclimatic principals. Figure 2\&3: introducing environmental problems and renewable sources.

Step 3: Teaching activities that require active collaborative participation of pre-service teachers are carried out. In order to help students consolidate these environmental concepts, they are asked to choose subjects from the following modules:

Table 1

\begin{tabular}{|l|}
\hline a) Excessive energy use and production \\
\hline b) Depletion of energy reserves \\
\hline c) Degradation of the natural environment \\
\hline d) Energy Saving \\
\hline e) Recycling \\
\hline f) Renewable sources \\
\hline g) Bioclimatic \\
\hline
\end{tabular}

Students are invited to express their views creating immobile and moving images through posters and films. For this reason, they are presented guidelines and techniques such as the slowmation technique, that is a slow animation that is: a) student-centered, b) used as a creative learning environment and c) runs with 2 photos per second providing a simplified way of creating digital narratives. Students have also been introduced to a) guidelines for developing handmade and/or digital posters and b) guidelines for using an educational wiki. This information has been used for developing the projects presented in Table 2 that follows:

Table 2

\begin{tabular}{|ll|}
\hline i) & a handmade poster paper \\
\hline ii) & a digital poster \\
\hline iii) & a slowmation film \\
\hline
\end{tabular}




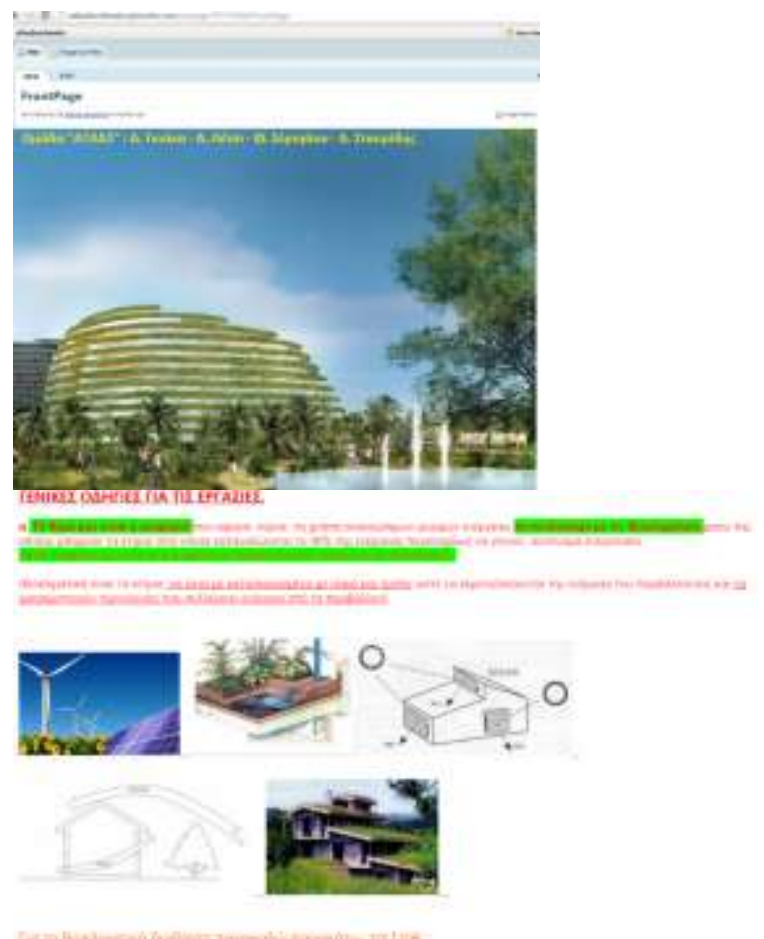

Figure 4: Wiki's frond page

Figure 5: Instructions on wiki's frond page

At the same time on the front page of a wiki specially designed for this implementation (Figures $4 \& 5$ ), all the educational material has been uploaded, including environmental issues, ways to use a wiki, guidelines for developing a poster, information and examples regarding how to create a movie with the slowmation technique (Brown, 2011; Hoban et al.,2007). Educational wikis belongs to social media technology and can be used in education by integrating different media types, facilitating co-operational training and linking directly and continuously the scientific research to everyday life. The educational wiki developed for our implementation (bttp: atlasbioclimatic.pbworks.com) operates in an internet environment for educational issues at the site (pbworks.com) and includes:

a) A front page where teachers-facilitators present general information, directions and instructions through hyperlinks (the front page is both a database and a site for programming and getting feedback concerning the process).

b) Pages where the students can place their papers, individually or in groups.

c) Uploaded presentations of students' applications, comments and feedback coming for them.

d) Social information from the educational applications. For every paper placed at the wiki, comments and intervention by the teachers and the rest of the students have been allowed as well as the history of the activities.

During the implementation, the wiki has been used as a forum of communication, cooperation and publication of the results of the application. 
Step 4: Digital narratives are designed and developed. The phases of the slowmation technique followed by the students are presented in Table 3:

Table 3
\begin{tabular}{|l|}
\hline 1. Writing of the script \\
\hline 2. Design and development of scenery and heroes \\
\hline 3. Direction guidelines \\
\hline 4. Taking photos (2 photos per second are needed) \\
\hline 5. Developing and recording the dialogues \\
\hline 6. Editing \\
\hline 7. Screening \\
\hline
\end{tabular}

The developed scripts describe the problems that derive from the use of non-sustainable energy sources, methods of exploitation renewable energy sources, the advantages of the use of sustainable energy sources, ways of saving resources and energy in our everyday life and the use of bio-climate methods. Students responded with enthusiasm in this educational program as it is attractive with innovative teaching practices that include role play, theater and art, used more often in modern teaching research with impressive learning outcomes (Preece, 2000; Seroglou, 2006; Piliouras et al., 2011, Gkioka et al. 2013). The way in which students express their ideas in this program varied. In their work, they focus on environmental problems that are created by the human environment and they propose solutions. Their posters introduce systems of renewable energy and the benefits of bioclimatic buildings and suggest energy-saving methods in our daily activities (Figures 6, $7 \& 8$ ).

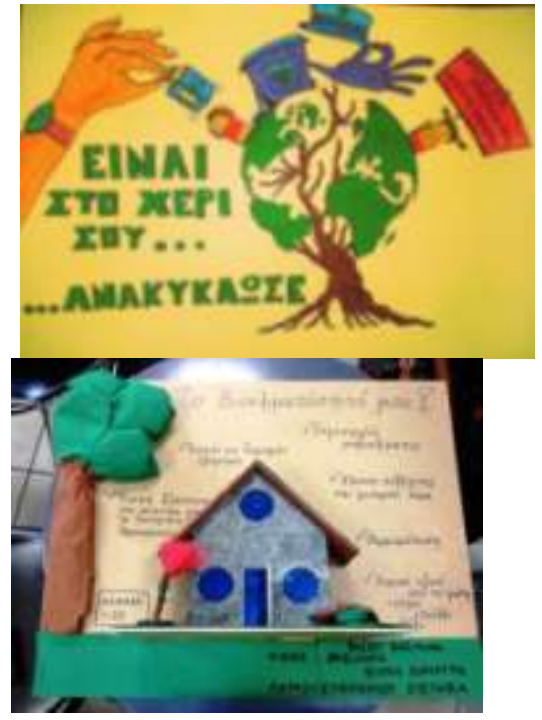

Figure 6: Students handmade posters bioclimatic model

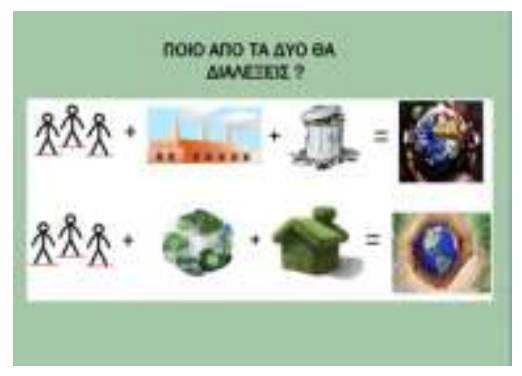

Figure 7: Students digital posters

Figure 8: Students handmaid 
Their slowmation scenarios describe the advantages of using renewable energy, the problems arising from the use of non-renewable energy, and suggestions for using recycling and bioclimatic applications in existing and new constructions (Figures 9, 10 \& 11).
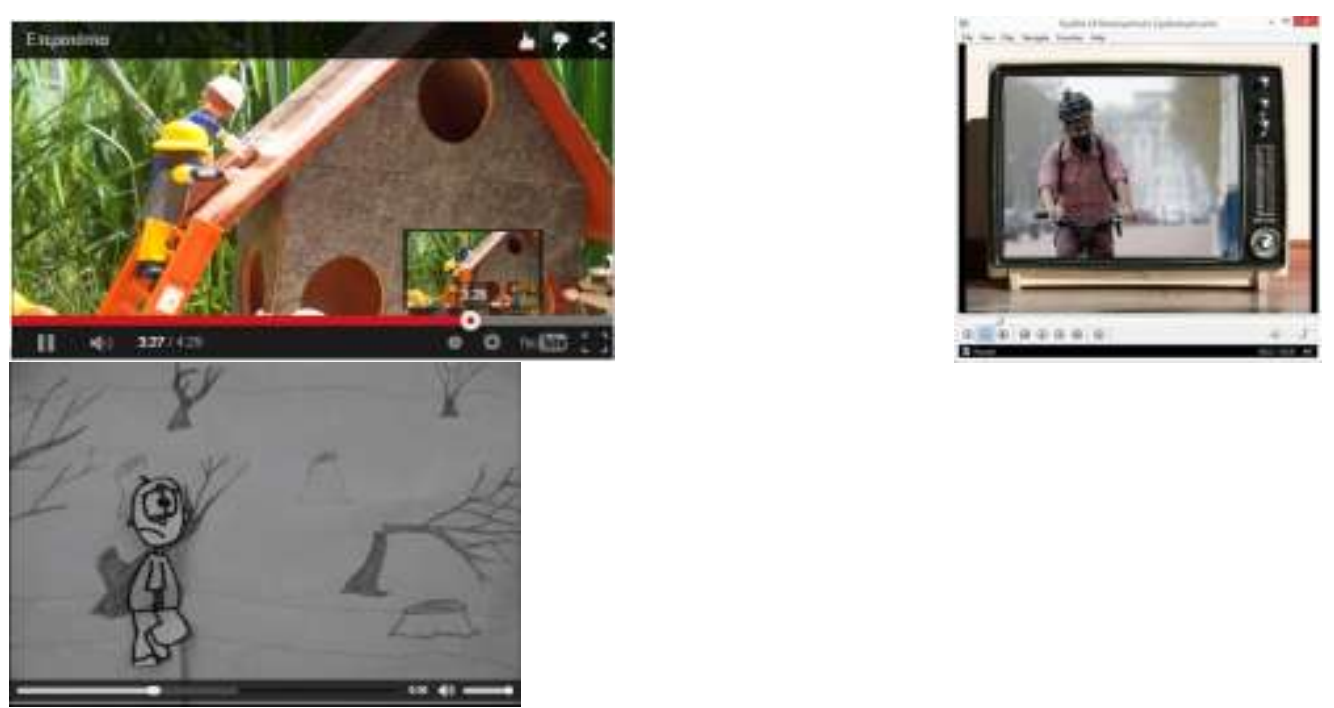

Figure 9, 10 \& 11: Students scenarios about bioclimatics \& environmental problems

Finally, students take photos of their paper posters and together with their digital posters and their slowmation films uploaded them on the wiki.

Step 5: Individual interviews and questionnaire distribution are carried out in order to record the impact of our application. The answers to the questionnaires before and after the implication show that although initially concepts such as bioclimatic architecture (Figure 14), sustainable development (Figure 12) and the amount of building energy consumption (Figure 13) are not well known to the students, at the end of the implementation, most students know about bioclimatic and sustainability and also that the building sector consumes large amounts of energy. 


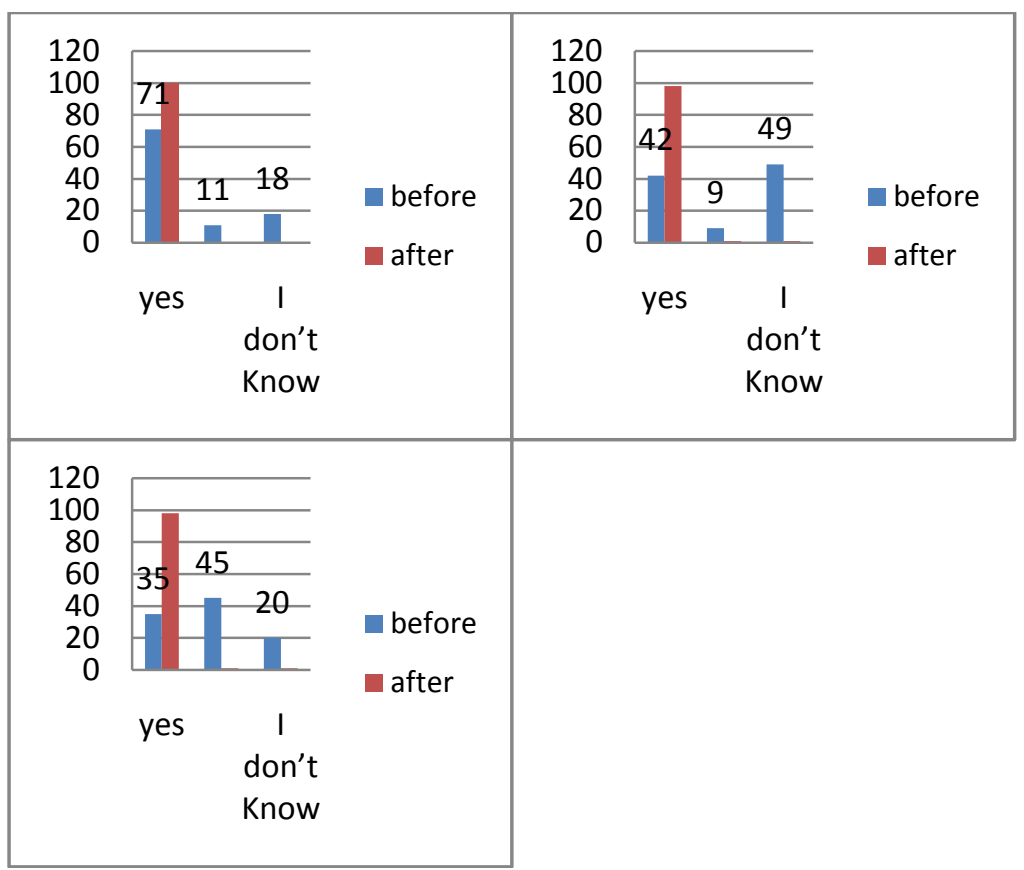

Figure 12, 13 \& 14

During the implementation students become familiar to knowledge concerning environmental issues that is most useful to pre-service teachers as citizens as well as educators.

Step 6: The recorded interviews, the questionnaires and the developed digital narratives are analyzed using the GNOSIS research model (Guidelines for Nature of Science Introduction to Scientific literacy - see Figure 15 below). 


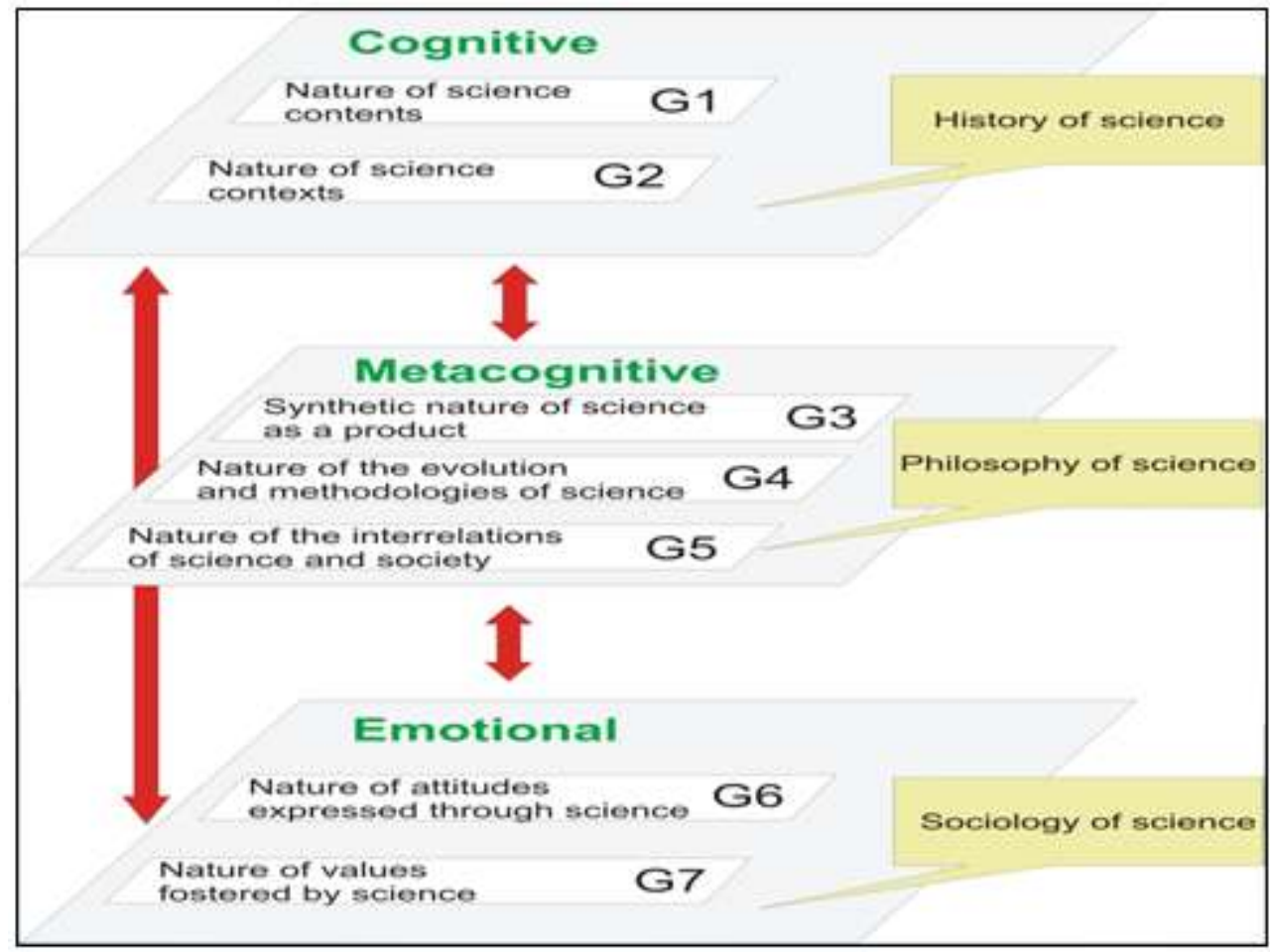

Figure 15: The GNOSIS research model

The pre-service teachers' digital narratives have been analyzed in flow charts every 5 seconds using the GNOSIS research model for pointing out the various aspects of the nature of science presented in the pre-servise teachers' science films (Seroglou \& AdurizBravo 2007). GNOSIS is a model for designing, developing and evaluating instructional material and teaching activities keeping a focus on nature of science and identifying the three complementary dimensions of learning: cognitive, meta-cognitive and emotional and linking them with three meta-sciences: history of science, philosophy of science and sociology of science:

1. The cognitive dimension, dealing both with science as a set of models that give meaning to the world (nature of science contents) and with the broader social contexts in which such ideas have come to be (nature of science contexts).

2. The meta-cognitive dimension, focusing on what science is (synthetic nature of science as a product), how science changes in history (nature of the evolution and methodologies of science), and how science relates to society and culture (nature of the interrelations of science and society, in which the 'cultural print of science' can be appreciated).

3. The emotional dimension, which opens the picture to considering attitudes (nature of attitudes expressed through science) and values (nature of values fostered by science) that are fundamental in scientifically literate citizens. 


\section{Results \& Discussion}

Data analysis initially shows encouraging results in terms of pre-service students re-contextualizing bioclimatics and sustainability concepts and attitudes. Linking science with digital narratives reveals a creative way of learning while students design and produce original learning material. Also, it is noted that the use of modern technology facilitates the teaching of environmental sciences as it incorporates new ideas and alternative means of learning such as teaching through images, computers and the internet which dominates our era, is stimulating while it facilitates communication and the diffusion of this information to the wider social audience. The series of courses on bioclimatics and sustainability introduces prospective teachers to the practical use of concepts and processes relevant to the saving of energy in buildings, the protection of the natural environment and the formation of a friendly man-made environment that is incorporated in the natural environment without destructive consequences. The methodology followed in our implementation can be applied to many other science and/or environmental topics.

\section{References}

Brown, J. (2011) The impact of student created slowmation on the teaching and learning of primary science. Post-graduate Thesis. School of Education Edith Cowan University, Perth, Western Australia.

Hoban, G., Ferry, B., Konza, D. \& Vialle W. (2007). Slowmation: exploring a new teaching approach in primary school classrooms. Proceedings of the 2007 Australian Teacher Education Association Conference.

Gkioka, A., Stavridis,D., Seroglou,F.: 2013, Interactive stories and interactive learning environments for sustainability and bioclimatic. Paper presented at the 7 th national ICT teaching conference,May17-19 2013.Syros, Greece.(in Greek)

Cunningam, D., Duffy T. \& Knuth R.: 1993, The textbook of the future. Ellis Horwood, London.

Seroglou, F. (2006). Science for citizenship. Epikentro publications. Thessaloniki. (in Greek)

Seroglou, F., \& Aduriz-Bravo, A. (2007). Designing and evaluating nature-of-science activities for teacher education. Paper presented at the 9th international history, philosophy and science teaching conference, June 24-28, 2007. Calgary, Canada.

Osberg K. M.: 1995, Virtual Reality and Education: Where Imagination and Experience Meet. VR in the Schools 1(2), pp. 1-3.

Piliouras, P., Siakas, S. \& Seroglou, F. : 2011, Pupils produce their own narratives inspired by the history of science: Animation movies concerning the geocentric-heliocentric debate. Science \& Education, 20(7): 761-795.

Preece, J.: 2000, Online communities: Designing usability, supporting sociability. J. Wiley \& Sons, New York. 